\title{
FORECASTING PERSEDIAAN BAHAN BAKU KERTAS MENGGUNAKAN METODE AUTOREGRESSIVE INTEGRATED MOVING AVERAGE (ARIMA) di YUDHARTA ADVERTISING
}

\author{
Mochammad Ainur Rofiq ${ }^{2}$, Walidini Syaihul Huda ${ }^{2}$ \\ Universitas Yudharta Pasuruan ${ }^{1}$, Universitas Bina Nusantara ${ }^{2}$ \\ Jl. Pondok Pesantren Ngalah No.16 Sengonagung Purwosari Pasuruan \\ email: arofiq428@gmail.com¹, walidini@yudharta.ac.id ${ }^{2}$
}

\begin{abstract}
Abstrak
Persediaan bahan baku memiliki peran penting bagi perusahaan karena akan mempengaruhi kemampuan perusahaan untuk memenuhi permintaan pelanggan. Berbagai kendala dapat timbul karena kurangnya bahan baku untuk produksi, seperti mengakibatkan keterlambatan untuk pemenuhan permintaan pelanggan. Karena penundaan ini, perusahaan mengalami beberapa kerugian. Dalam rangka mengatasi hal ini, perusahaan membutuhkan perencanaan dalam berbagai cara, terutama perencanaan yang berkaitan dengan inventori. Salah satu bentuk perencanaan persediaan adalah untuk memprediksi pasokan bahan baku untuk setiap waktu. Metode ARIMA (Autoregressive terpadu Moving Average) adalah metode prediktif dalam data mining untuk data time series. ARIMA dikatakan memiliki tingkat akurasi yang tinggi untuk peramalan jangka pendek dengan dataset minimal. Diperoleh model ARIMA $(0,1,1)$ untuk kertas art cartoon pada bulan Mei 2019 diperoleh hasil 297 dan pada Juni 2019 diperoleh hasil sebanyak 305 dengan nilai MSE 391,00, dan MAPE 21,74\%. Adapun kertas art cartoon 260 gram ditemukan model ARIMA $(0,1,2)$ dengan hasil peramalan Mei 2019 = 122 dan pada bulan Juni 2019 = 330 dengan nilai MSE 468,04, MAPE 22,87\%.
\end{abstract}

Kata Kunci : Yudharta Advertising, Persediaan Bahan Baku, ARIMA.

\section{PENDAHULUAN}

Sebuah perusahaan tidak bisa serta merta menetukan berapa, bagaimana, dan kapan harus memenuhi stok persediaan bahan baku untuk proses produksi karena untuk menghindari beberapa kemungkinan yang tidak diharapkan seperti terjadinya penumpukan bahan baku,berkurangnya kualitas bahan baku karena penyimpanan yang terlalu lama, keuangan menjadi tidak seimbang karena terhambat pada barang mentah (bahan baku) [1].

Bahan baku adalah bahan atau barang yang disimpan yang akan digunakan untuk memenuhi tujuan tertentu, misalnya untuk digunakan dalam proses produksi atau perakitan, untuk dijual kembali, atau untuk suku cadang dari suatu peralatan atau mesin [2]. Persediaan adalah sebagai suatu aktiva yang meliputi barang-barang milik perusahaan dengan maksud untuk dijual dalam suatu periode usaha yang normal, atau persediaan barang-barang masih dalam pengerjaan/ proses produksi, ataupun persediaan barang baku yang menunggu penggunaannya dalam suatu proses produksi[3]. Bahan baku adalah bahan utama dari suatu produk atau barang. Keberadaan bahan baku sangatlah penting dalam kelancaran proses produksi bahan baku mutlak ada jika perusahaan akan melakukan produksi[4]. Dengan adanya bahan baku ada beberapa keuntungan yang dapat diperoleh, yaitu:

1. Mencegah hilangnya kesempatan untuk menjual

Apabila jumlah persediaan bahan baku kurang, maka proses produksi akan mengalami hambatan yang akhirnya permintaan konsumen tidak dapat terpenuhi. Dengan kondisi seperti ini, konsumen akan mencari perusahan lain untuk memperoleh barang yang dibutuhkan. Oleh karena itu perusahaan dituntut untuk memberikan pelayanan yang memuaskan kepada konsumen agar mereka tidak berpaling kepada perusahaan lain.

2. Mendapat manfaat dari potongan harga

Pembelian dalam jumlah yang besar akan memberikan keuntungan berapa besar potongan harga. Untuk bahan baku yang dapat disimpan lama dan tersedia secara penyimpanan yang baik biasanya perusahaan akan membeli persediaan dalam jumlah yang besar.

3. Menjamin kelancaran proses produksi 
Dengan adanya persediaan yang sesuai dengan kebutuhan, maka perusahaan tidak akan mengalami kesulitan dalam proses produksi.

4. Mengurangi biaya perusahaan

Biaya pemesanan dapat ditekan jika perusahaan membeli barang dalam jumlah yang besar, sehingga frekuensi pemesanan dalam suatu periode dapat dikurangi.

Persediaan bahan baku memiliki peranan penting dalam sebuah perusahaan karena bahan baku adalah barang yang dibeli dari pemasok ataupun diolah sendiri oleh perusahaan untuk digunakan dalam proses produksi[5]. Bahan baku juga merupakan bahan yang membentuk bagian besar produk jadi, dalam perolehannya bahan baku dapat diperoleh dari pembelian lokal import atau hasil pengolahan sendiri[6].

Penelitian yang dilakukan Muh. Tholib (2016) dengan judul Peramalan Penjualan Dalam Rangka Perencanaan Produksi Pada Perusahaan Furniture (Studi Kasus CV. Budi Luhur Sidoarjo) menyimpulkan bahwa hasil peramalan dengan metode ARIMA yang sesuai untuk peramalan kursi adalah model ARIMA $(2,1,1)$ dengan nilai kesalahan MPE $0,194139 \%$ dan MAPE $21,4579 \%$. Sedangkan untuk peramalan penjualan meja dengan metode ARIMA diperoleh model ARIMA $(1,1,1)$ dengan kesalahan nilai MPE $0,4749 \%$ dan MAPE 15,2762\%. Sedangkan untuk metode Winters, konstanta pemulusan untuk penjualan kursi adalah dengan nilai kesalahan MPE $0,132045 \%$ dan MAPE $27,2516 \%$. sedangkan untuk peramalan penjualan meja, konstanta pemulusan adalah dengan nilai kesalahan MPE 0,332453\% dan MAPE 33,2453\%. pengembangan Master Production Schedule mengacu pada hasil peramalan dengan metode ARIMA karena metode tersebut memiliki nilai kesalahan yang lebih kecil daripada metode Winters[7].

Pada penelitian yang dilakukan Tri Oktarina dan Rasmila (2018) dengan judul Peramalan Produksi Crude Palm Oil (CPO) Menggunakan Metode ARIMA Pada PT. Sampoerna AGRO TBK menyimpulkan bahwa dari proses pengolahan data diidentifikasikan terdapat dua model ARIMA yang dapat digunakan dalam meramalkan jumlah produksi minyak sawit mentah yaitu ARIMA $(1,1,3)$ dan ARIMA $(1,1,0)$. kedua model tersebut diuji kembali dengan diagnosa residual, hasil dari diagnosa residual didapatkan model ARIMA terbaik yakni ARIMA $(1,1,0)$, dan nilai estimasi peramalan pada 24 periode yakni periode Januari 2018 sampai Desember 2019 mengalami peningkatan setiap bulannya, namun berdasarkan tahun, hasil produksi mengalami penurunan produksi pada tahun 2018 sebesar 295.478 ton dari tahun sebelumnya dan mengalami peningkatan produksi Crude Palm Oil (CPO) pada tahun 2019 sebesar 332.306 ton. Ketidakstabilan produksi Calm Palm Oil (CPO) disebabkan beberapa indikasi seperti faktor alam atau iklim, indikasi hama dan penyakit tanaman, dan kesalahan yang disebabkan oleh Human Error[8].

Penelitian ini menggunakan metode yang sama dari penelitian-penelitian sebelumnya yakni metode ARIMA, untuk objek yang akan diteliti adalah kertas art cartoon 230 gram dan kertas art cartoon 260.

\section{Metode Penelitian}

\subsection{Data Set}

Data dalam penelitian ini merupakan data Art Paper mulai dari bulan Januari 2018 sampai April 2019 sebanyak 5758 data yang terdiri dari 2 variabel. Untuk pengambilan data peneliti mengambil data primer dari data laporan bulanan Yudharta Advertising yang berbentuk excel, kemudian peneliti mengambil data Art Cartoon yang terdapat di dalam laporan bulanan tersebut.

Tabel 1. Data Kertas Art Cartoon 230 dan 260 gram

\begin{tabular}{ccccc}
\hline \multirow{2}{*}{ No. Periode } & & \multicolumn{2}{c}{ Jenis Kertas Art Paper } \\
\cline { 3 - 4 } & Bulan & Tahun & $\mathbf{2 3 0}$ & $\mathbf{2 6 0}$ \\
\hline 1 & Agustus & & 129 & 13 \\
2 & September & & 239 & 2 \\
3 & Oktober & 2017 & 94 & 23 \\
4 & November & & 114 & 63 \\
5 & Desember & & 90 & 50 \\
6 & Januari & & 171 & 76 \\
7 & Februari & & 475 & 1 \\
8 & Maret & & 313 & 154 \\
9 & April & & 244 & 28 \\
10 & Mei & 26 & 21 \\
11 & Juni & 2018 & 27 & 118 \\
12 & Juli & & 105 & 26 \\
13 & Agustus & & 154 & 84 \\
14 & September & & 177 & 44 \\
15 & Oktober & & 327 & 73 \\
16 & Nopember & & 15 & 101
\end{tabular}




\begin{tabular}{|c|c|c|c|c|}
\hline 17 & Desember & & 74 & 206 \\
\hline \multirow[b]{2}{*}{ No. } & \multicolumn{2}{|c|}{ Periode } & \multicolumn{2}{|c|}{ Jenis Kertas Art Paper } \\
\hline & Bulan & Tahun & 230 & 260 \\
\hline 18 & Januari & \multirow{5}{*}{2019} & 164 & 17 \\
\hline 19 & Februari & & 253 & 250 \\
\hline 20 & Maret & & 60 & 101 \\
\hline 21 & April & & 972 & 461 \\
\hline & Total & & 4223 & 1912 \\
\hline
\end{tabular}

\section{Hasil dan Analisis}

\subsection{Identifikasi Time Series Plot}

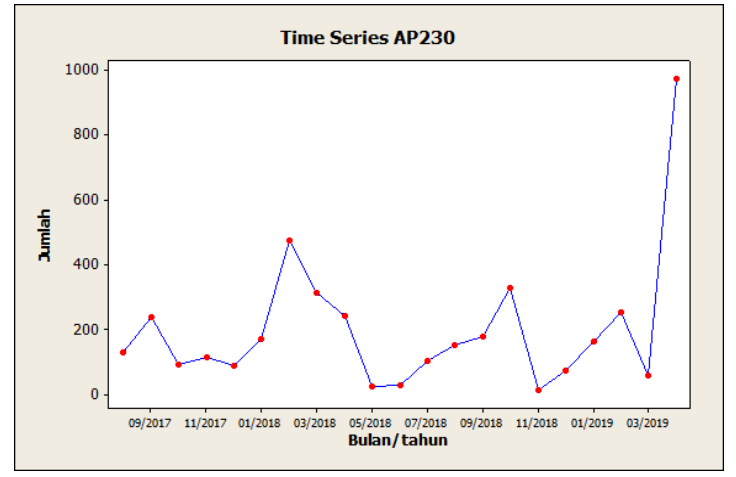

Gambar 1. Time Series Kertas Art Cartoon 230

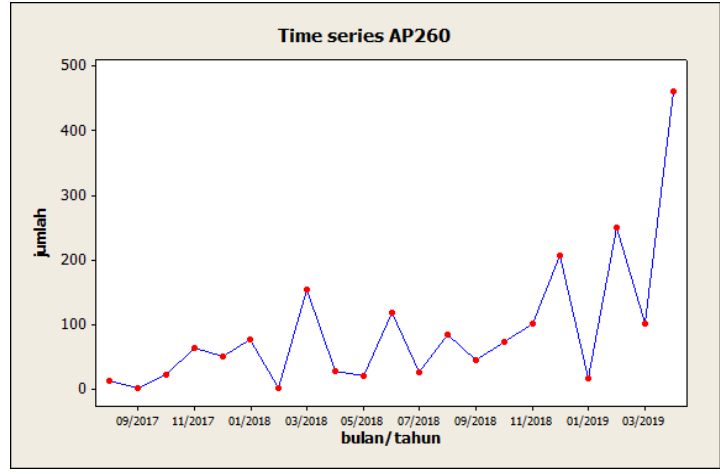

Gambar 2. Time Series Kertas Art Cartoon 260 Gram

Gambar 1 menunjukkan bahwa bahan baku kertas art cartoon dengan gramatur 230 gram terjadi fluktuatif dari bulan Agustus 2017 sampai bulan April 2019. Kebutuhan bahan baku ini mengalami kenaikan dari bulan Januari 2018 ke Februari 2018, kemudian mengalami penurunan hingga pada bulan Maret 2018, akan tetapi dalam pola ini terdapat kenaikan secara drastis yaitu dari bulan Maret 2019 ke bulan April 2019. Pola tersebut menunjukkan bahwa terdapat pola musiman yang terjadi untuk bahan baku kertas art cartoon 230 gram.

Gambar 2 menunjukkan bahwa bahan baku kertas art cartoon dengan gramatur 260 gram terjadi fluktuatif penggunaan mulai bulan Agustus 2017 sampai bulan April 2019, dari setiap bulan terjadi fluktuatif normal terkecuali mulai bulan Desember 2018 sampai April 2019, bahan baku kertas art cartoon dengan gramatur 260 ini mengalami fluktuatif secara tidak normal. Dalam gambar tersebut mengindikasikan bahwa gambar 2 memiliki pola musiman.

Kemudian dilakukan proses transformasi data agar data stasioner terhadap varian menggunakan bantuan program minitab sebagai berikut:

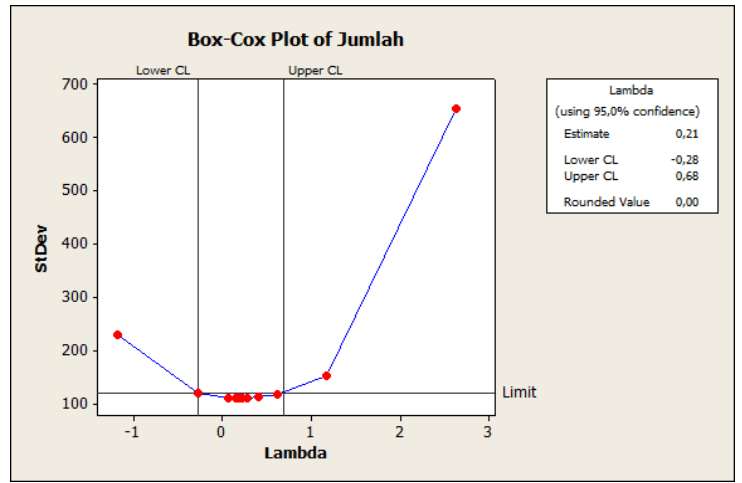

Gambar 3. Plot Box-Cox Kertas Art Cartoon 230 Gram

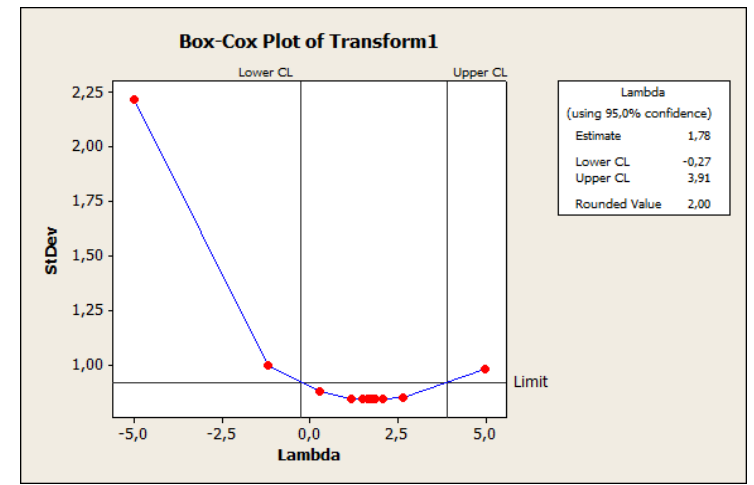

Gambar 4.. Transformasi Kedua Box-Cox Kertas Art Cartoon 230 Gram

Dalam gambar 3 didapatkan nilai rounded value 0,00, yang dikatakan data masih belum stasioner terhadap varian, maka dilakukan transformasi Box-Cox kedua seperti pada gambar 4. 
Pada gambar 4, data masih tidak dapat disebut stasioner karena nilai rounded value 2,00, maka data harus ditransformasikan lagi agar didapatkan data yang stasioner seperti pada gambar 5 berikut.

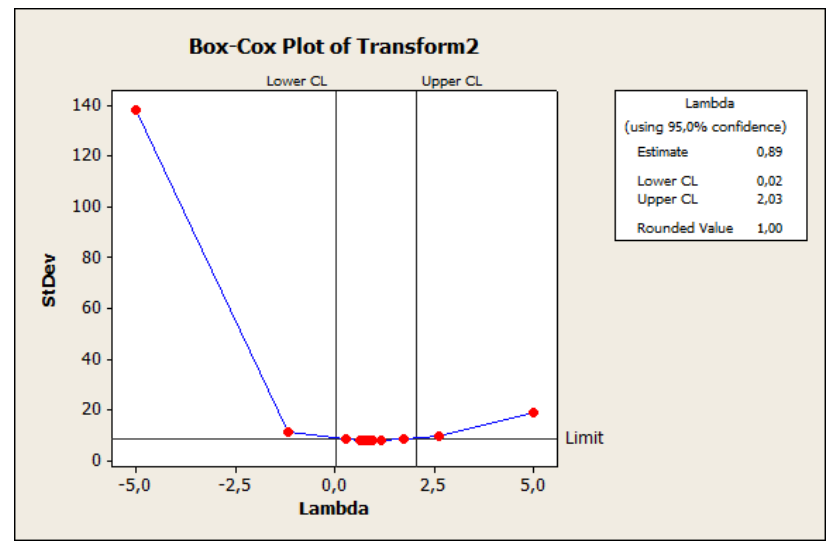

Gambar 5. Tranformasi Ketiga Box-Cox Kertas Art Cartoon 230 Gram

Pada gambar 5, didapatkan nilai rounded value 1,00 yang dikatakan data telah stasioner terhadap varian. Berikut hasil dari transformasi data mulai awal hingga transformasi ketiga:

Tabel 2. Transformasi Kertas Art Cartoon 230 Gram

\begin{tabular}{llll}
\hline $\begin{array}{c}\text { Kertas art cartoon } \\
\text { 230 gram }\end{array}$ & Transformasi $\mathbf{1}$ & Transformasi 2 & Transformasi 3 \\
\hline 129 & 4,85981 & 23,6178 & 23,6178 \\
239 & 5,47646 & 29,9917 & 29,9917 \\
94 & 4,54329 & 20,6415 & 20,6415 \\
114 & 4,73620 & 22,4316 & 22,4316 \\
90 & 4,49981 & 20,2483 & 20,2483 \\
171 & 5,14166 & 26,4367 & 26,4367 \\
475 & 6,16331 & 37,9864 & 37,9864 \\
313 & 5,74620 & 33,0189 & 33,0189 \\
244 & 5,49717 & 30,2189 & 30,2189 \\
26 & 3,25810 & 10,6152 & 10,6152 \\
27 & 3,29584 & 10,8625 & 10,8625 \\
105 & 4,65396 & 21,6593 & 21,6593 \\
154 & 5,03695 & 25,3709 & 25,3709 \\
177 & 5,17615 & 26,7925 & 26,7925 \\
327 & 5,78996 & 33,5236 & 33,5236 \\
15 & 2,70805 & 7,3335 & 7,3335 \\
74 & 4,30407 & 18,5250 & 18,5250 \\
164 & 5,09987 & 26,0086 & 26,0086 \\
253 & 5,53339 & 30,6184 & 30,6184 \\
60 & 4,09434 & 16,7637 & 16,7637 \\
972 & 6,87936 & 47,3255 & 47,3255 \\
\hline
\end{tabular}

Hasil dari transformasi ketiga dari data kertas art cartoon 230 gram diubah menjadi grafik plot data tren seperti pada gambar 6 .

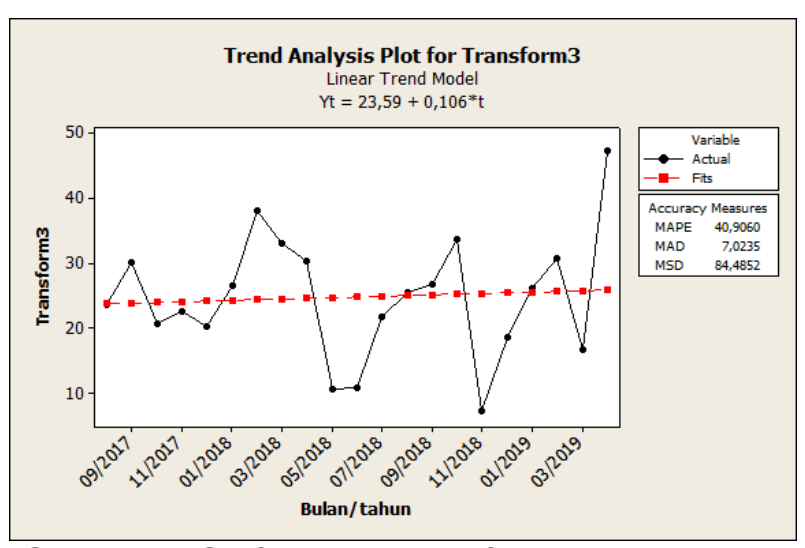

Gambar 6. Grafik Trend Transformasi Ketiga Box- 
Cox Kertas Art Cartoon 230 Gram

Pada gambar 6 dapat dilihat dengan jelas bahwa grafik trend belum bisa mengatasi kestasioneran data dalam rata-rata, maka perlu dilakukannya differencing terhadap data asli.

Dari data hasil transformasi kemudian dilakukan proses differencing pada data kertas art cartoon 230 dan didapatkan hasil sebagai berikut:

Tabel 3. Differencing Kertas Art Cartoon 230 Gram

\begin{tabular}{rll}
\hline \multicolumn{1}{c}{$\boldsymbol{Z}_{\boldsymbol{t}}$} & \multicolumn{1}{c}{$\boldsymbol{Z}_{\boldsymbol{t}-\mathbf{1}}$} & \multicolumn{1}{c}{$\boldsymbol{Y}_{\boldsymbol{t}}$} \\
\hline 23,6178 & & $*$ \\
29,9917 & 23,6178 & 6,3739 \\
20,6415 & 29,9917 & $-9,3501$ \\
22,4316 & 20,6415 & 1,79 \\
20,2483 & 22,4316 & $-2,1833$ \\
26,4367 & 20,2483 & 6,1884 \\
37,9864 & 26,4367 & 11,5497 \\
33,0189 & 37,9864 & $-4,9676$ \\
30,2189 & 33,0189 & $-2,8$ \\
10,6152 & 30,2189 & $-19,604$ \\
10,8625 & 10,6152 & 0,2473 \\
21,6593 & 10,8625 & 10,7968 \\
25,3709 & 21,6593 & 3,7115 \\
26,7925 & 25,3709 & 1,4216 \\
33,5236 & 26,7925 & 6,7311 \\
7,3335 & 33,5236 & $-26,19$ \\
18,525 & 7,3335 & 11,1914 \\
26,0086 & 18,525 & 7,4837 \\
30,6184 & 26,0086 & 4,6098 \\
16,7637 & 30,6184 & $-13,855$ \\
47,3255 & 16,7637 & 30,5619 \\
\hline
\end{tabular}

Dalam gambar 7 grafik hasil transformasi dilakukan differencing agar data dapat stasioner dalam rata-rata. Untuk data kertas art cartoon 260 gram, grafik kestasioneran data dapat ditunjukkan pada gambar 8.

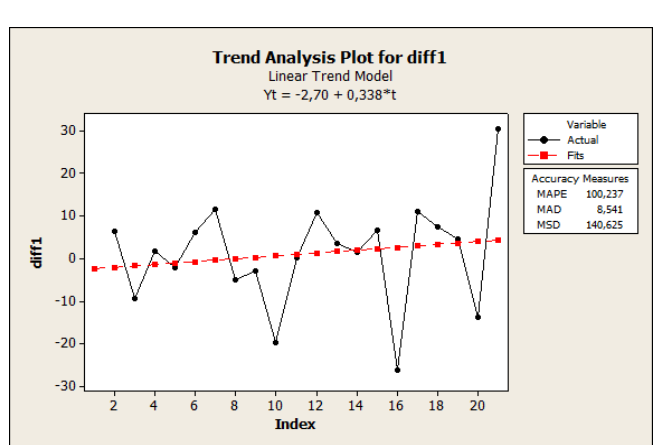

Gambar 7. Grafik Tren Data Kertas Art Cartoon 230

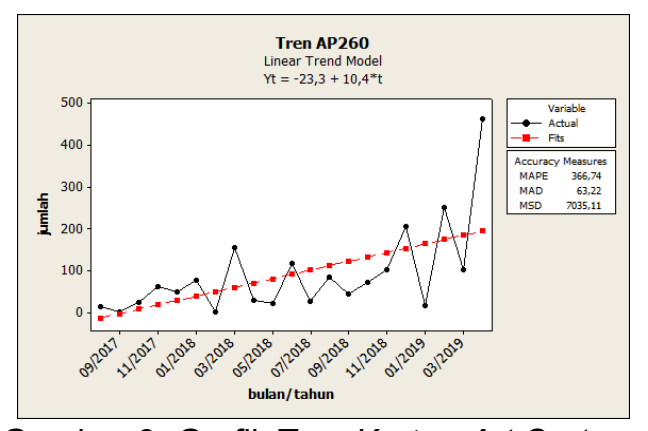

Gambar 8. Grafik Tren Kertas Art Cartoon 260 Gram

Pada grafik tren kertas art cartoon 260 gram secara visual data dalam plot menunjukkan data tidak stasioner, maka data harus distasionerkan terlebih dahulu agar dapat digunakan untuk peramalan. Dalam grafik tersebut juga menunjukkan sebuah tren mulai dari bulan Agustus 2017 April 2019. Langkah untuk menstasionerkan data dalam hal ini akan dilakukan proses transformasi data agar stasioner terhadap ragam/varians. Berikut proses transformasi data yang pertama dilakukan dalam gambar 9 .
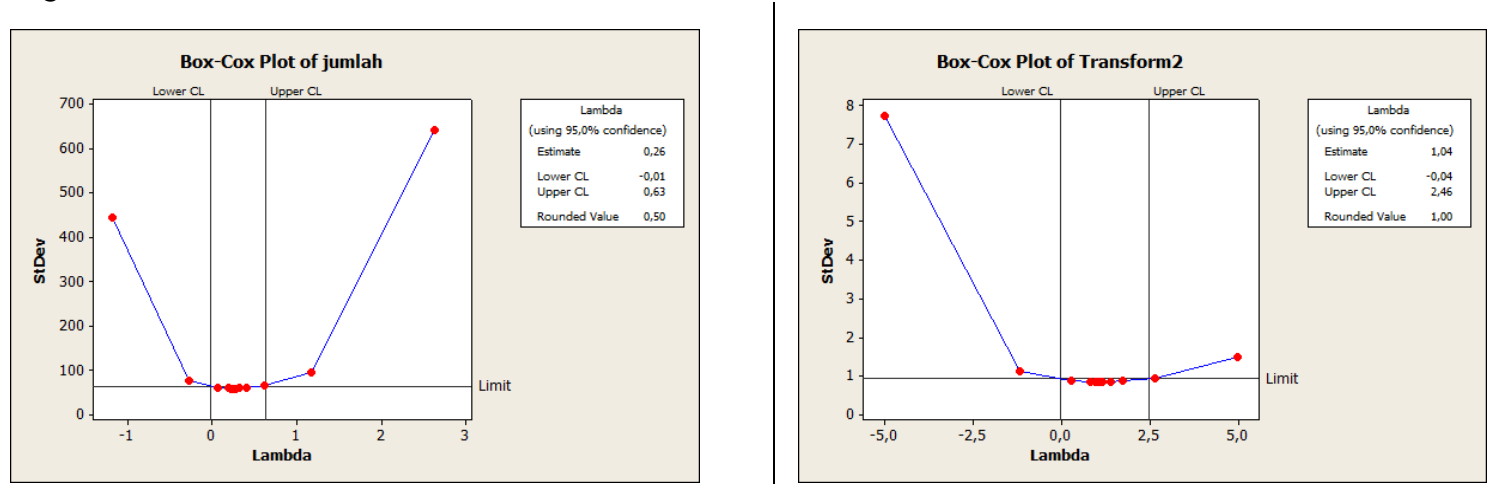
Gambar 9. Transformasi Box-Cox Kertas Art Cartoon 260 Gram

Pada gambar 9 menjelaskan bahwa hasil transformasi dari data kertas art cartoon 260 gram memiliki rounded value sebesar 0,50 , dari nilai rounded value tersebut dapat diketahui bahwa data belum stasioner dalam ragam/varian, maka harus dilakukan transformasi Box-Cox lagi untuk mendapatkan data yang stasioner dalam ragam/varian. Berikut hasil transformasi kedua pada gambar 10.

Setelah transformasi pertama selesai dilakukan didapatkan nilai lambda sebesar 1,04, maka data kertas art cartoon 260 gram dikatakan telah stasioner. Pada gambar 10 ditunjukkan bahwa nilai rounded value hasil transformasi sebesar 1,00 , berikut didapatkan nilai dari hasil transformasi sebagai berikut:

Tabel 4. Transformasi Kertas Art Cartoon 260 Gram

\begin{tabular}{lll}
\hline $\begin{array}{l}\text { Kertas art cartoon } \\
\mathbf{2 3 0} \text { gram }\end{array}$ & Transformasi1 & Transformasi2 \\
\hline 13 & 3,60555 & 1,89883 \\
2 & 1,41421 & 1,18921 \\
23 & 4,79583 & 2,18994 \\
63 & 7,93725 & 2,81731 \\
50 & 7,07107 & 2,65915 \\
76 & 8,7178 & 2,95259 \\
1 & 1 & 1 \\
154 & 12,4097 & 3,52274 \\
28 & 5,2915 & 2,30033 \\
21 & 4,58258 & 2,1407 \\
118 & 10,8628 & 3,29587 \\
26 & 5,09902 & 2,2581 \\
84 & 9,16515 & 3,0274 \\
44 & 6,63325 & 2,57551 \\
73 & 8,544 & 2,92301 \\
101 & 10,0499 & 3,17015 \\
206 & 14,3527 & 3,7885 \\
17 & 4,12311 & 2,03054 \\
250 & 15,8114 & 3,97635 \\
101 & 10,0499 & 3,17015 \\
461 & 21,4709 & 4,63367 \\
\hline & & \\
\hline
\end{tabular}

Tabel 5. Differencing Kertas Art Cartoon 260

\begin{tabular}{lll}
\multicolumn{3}{c}{ Gram } \\
\hline \multicolumn{1}{c}{$\boldsymbol{Z}_{\boldsymbol{t}}$} & \multicolumn{1}{c}{$\boldsymbol{Z}_{\boldsymbol{t}-\mathbf{1}}$} & \multicolumn{1}{c}{$\boldsymbol{Y}_{\boldsymbol{t}}$} \\
\hline 1,89883 & & ${ }^{*}$ \\
1,18921 & 1,89883 & $-0,7096$ \\
2,18994 & 1,18921 & 1,00073 \\
2,81731 & 2,18994 & 0,62737 \\
2,65915 & 2,81731 & $-0,1582$ \\
2,95259 & 2,65915 & 0,29344 \\
1 & 2,95259 & $-1,9526$ \\
3,52274 & 1 & 2,52274 \\
2,30033 & 3,52274 & $-1,2224$ \\
2,1407 & 2,30033 & $-0,1596$ \\
3,29587 & 2,1407 & 1,15518 \\
2,2581 & 3,29587 & $-1,0378$ \\
3,0274 & 2,2581 & 0,7693 \\
2,57551 & 3,0274 & $-0,4519$ \\
2,92301 & 2,57551 & 0,3475 \\
3,17015 & 2,92301 & 0,24714 \\
3,7885 & 3,17015 & 0,61834 \\
2,03054 & 3,7885 & $-1,758$ \\
3,97635 & 2,03054 & 1,94581 \\
3,17015 & 3,97635 & $-0,8062$ \\
4,63367 & 3,17015 & 1,46352 \\
\hline & &
\end{tabular}

Maka data disebut sudah stasioner dalam ragam/varian, maka data memasuki proses differencing untuk membuat data stasioner dalam rata-rata. Pada data hasil transformasi dilakukan differencing untuk mendapatkan data yang stasioner dalam rata-rata. Data hasil differencing pertama dari kertas art cartoon 260 gram pada tabel 5.

Dalam grafik tren (gambar 11) ditampilkan grafik yang memvisualisasikan hasil dari transformasi kedua data art cartoon 260 gram yang sudah stasioner.

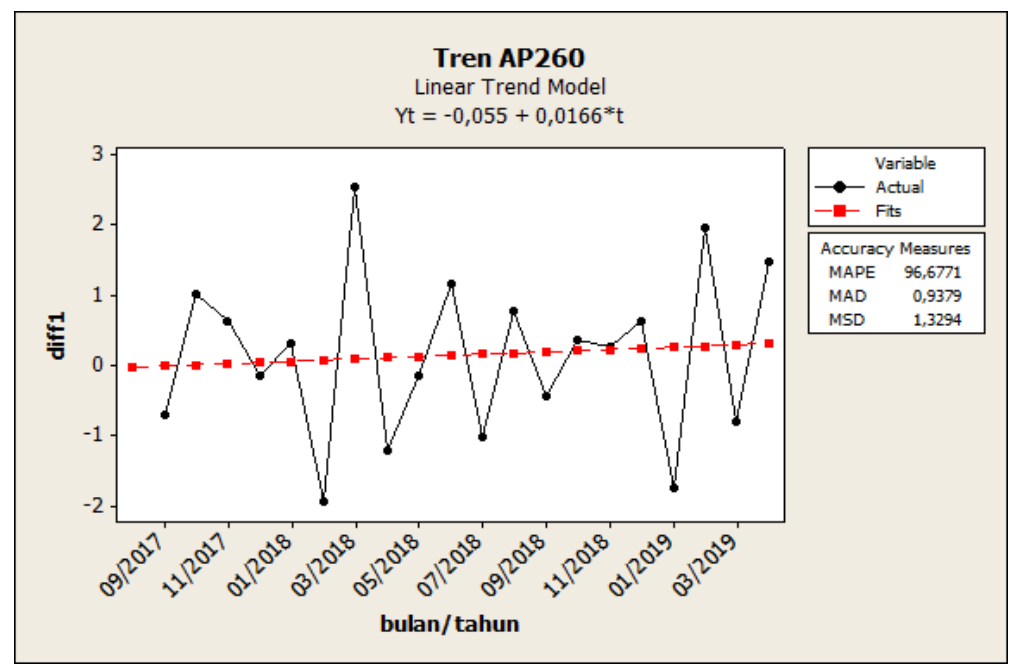

Gambar 11. Grafik Tren Data Art Cartoon 260 Gram Stasioner

1. Identifikasi Model 
Identifikasi model ARIMA dilakukan untuk mendapatkan nilai dugaan model ARIMA dengan melihat plot ACF (Autocorrelation Function) dan PACF (Partial Autocorrelation Function). Berikut hasil perhitungan plot ACF pada kertas art cartoon 230 gram.

Table 6. Nilai ACF Kertas Art Cartoon 230 Gram

\begin{tabular}{cc}
\hline $\begin{array}{c}\text { Koefisien } \\
\text { Autokorelasi }\end{array}$ & Nilai Plot ACF \\
\hline$\hat{\rho}_{0}$ & 1 \\
$\hat{\rho}_{1}$ & $-0,27082$ \\
$\hat{\rho}_{2}$ & $-0,07023$ \\
$\hat{\rho}_{3}$ & $-0,13905$ \\
$\hat{\rho}_{4}$ & 0,076761 \\
$\hat{\rho}_{5}$ & $-0,2076$ \\
$\hat{\rho}_{6}$ & $-0,07023$ \\
\hline
\end{tabular}

Setelah nilai koefisien autokorelasi ditemukan, kemudian dihitung nilai PACF dan ditemukan hasil perhitungan dari plot PACF sebagai berikut:

Table 7. Nilai PACF Kertas Art Cartoon 230 gram

\begin{tabular}{lc}
$\begin{array}{c}\text { Partial } \\
\text { Koefisien } \\
\text { Autokorelasi }\end{array}$ & $\begin{array}{c}\text { Nilai Partial } \\
\text { Koefisien } \\
\text { Autokorelasi }\end{array}$ \\
\hline$\hat{\alpha}_{11}$ & $-0,27082$ \\
$\hat{\alpha}_{22}$ & $-0,15493$ \\
$\hat{\alpha}_{33}$ & $-0,22442$ \\
$\hat{\alpha}_{44}$ & $-0,05606$ \\
$\hat{\alpha}_{55}$ & $-0,28654$ \\
\hline
\end{tabular}

Berikut adalah plot ACF dan PACF dari data kertas art cartoon 230 dan 260 gram. Pada gambar 12 merupakan plot ACF dan PACF kertas art cartoon 230 gram. Akan dijelaskan sebagai berikut:
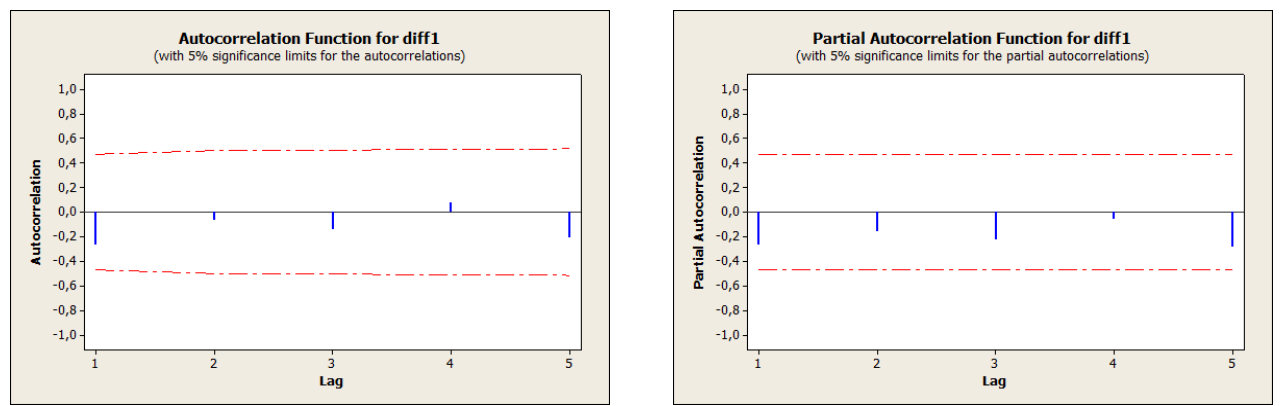

Gambar 12. Plot ACF dan PACF Kertas Art Cartoon 230 Gram

Berdasarkan plot ACF dan PACF pada gambar 12 ditemukan beberapa model ARIMA sebagai berikut:

Tabel 8. Model ARIMA Kertas Kertas Art Cartoon 230 gram

\begin{tabular}{cc}
\hline Model & ARIMA yang ditemukan \\
ARIMA $(0,1,1)$ & ARIMA $(1,1,0)$ \\
ARIMA $(0,1,2)$ & ARIMA $(2,1,0)$ \\
\hline
\end{tabular}

Setelah model dugaan sementara ARIMA ditemukan, maka akan dilakukan tahap estimasi parameter model yang berfungsi untuk menetukan model yang sesuai dengan data, model yang berdistribusi normal dan lain-lain.

Untuk kertas art cartoon 260 gram didapatkan hasil perhitungan untuk plot ACF dan PACF dalam tabel 9 dan tabel 10.

Tabel 9. Nilai ACF Kertas Art Cartoon 260 gram

\begin{tabular}{|c|c|}
\hline $\begin{array}{c}\text { Koefisien } \\
\text { Autokorelasi }\end{array}$ & Nilai Plot ACF \\
\hline$\hat{\rho}_{0}$ & 1 \\
\hline$\hat{\rho}_{1}$ & $-0,6951$ \\
\hline$\hat{\rho}_{2}$ & 0,29312 \\
\hline$\hat{\rho}_{3}$ & $-0,0496$ \\
\hline$\hat{\rho}_{4}$ & $-0,1347$ \\
\hline$\hat{\rho}_{5}$ & 0,19953 \\
\hline
\end{tabular}

Setelah nilai ACF ditemukan kemudian dicari nilai PACF sebagai berikut

Tabel 10. Nilai PACF Kertas Art Cartoon 260 gram

\begin{tabular}{lc}
$\begin{array}{c}\text { Partial } \\
\text { Koefisien } \\
\text { Autokorelasi }\end{array}$ & $\begin{array}{c}\text { Nilai Partial Koefisien } \\
\text { Autokorelasi }\end{array}$ \\
\hline$\hat{\alpha}_{11}$ & $-0,27082$ \\
$\hat{\alpha}_{22}$ & $-0,15493$ \\
$\hat{\alpha}_{33}$ & $-0,22442$ \\
$\hat{\alpha}_{44}$ & $-0,05606$
\end{tabular}




$\begin{array}{lllll}\hat{\rho}_{6} & -0,6951 & \hat{\alpha}_{55} & -0,28654\end{array}$

Selanjutnya data hasil perhitungan divisualisasikan dalam bentuk plot ACF dan plot PACF, gambar 13 adalah gambar plot ACF kertas art cartoon 260 gram dan gambar 13 adalah gambar plot PACF kertas art cartoon 260 gram.
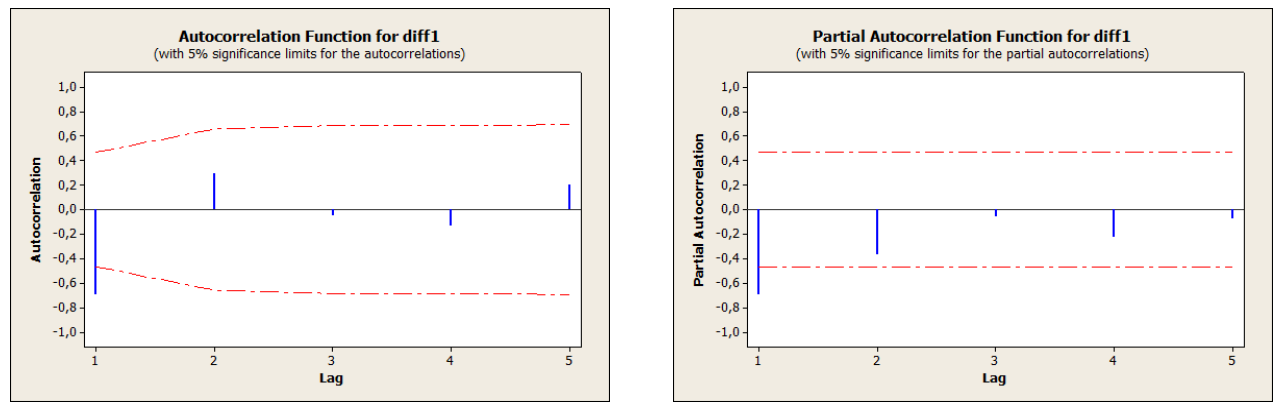

Gambar 13. Plot ACF dan PACF Kertas Art Cartoon 260 Gram

Berdasarkan plot ACF dan PACF pada gambar 13 ditemukan beberapa model ARIMA sebagai berikut:

Tabel 11. Model ARIMA Kertas Art Cartoon 260 gram

\begin{tabular}{ll}
\hline \multicolumn{2}{c}{ Model ARIMA yang ditemukan } \\
\hline ARIMA $(0,1,1)$ & ARIMA $(1,1,0)$ \\
ARIMA $(0,1,2)$ & ARIMA $(2,1,0)$ \\
\hline
\end{tabular}

2. Estimasi Parameter

Tahap estimasi parameter merupakan tahapan yang bertujuan untuk mengetahui nilai nilai model yang telah ditemukan dari plot ACF dan PACF. Berikut penjelasan hasil estimasi parameter model ARIMA pada kertas art cartoon 230 gram:

Tabel 12. Estimasi Parameter Model ARIMA Kertas

\begin{tabular}{|c|c|c|c|c|c|}
\hline \multicolumn{6}{|c|}{ Art Cartoon 230 gram } \\
\hline No & $\begin{array}{l}\text { Model } \\
\text { ARIMA }\end{array}$ & Parameter & Koefisien & $\begin{array}{c}p- \\
\text { value }\end{array}$ & MSE \\
\hline 1 & $\begin{array}{c}\text { ARIMA } \\
(0,1,1)\end{array}$ & $\theta_{1}$ & 0,914 & 0,000 & 50300 \\
\hline 2 & $\begin{array}{l}\text { ARIMA } \\
(0,1,2)\end{array}$ & $\begin{array}{l}\theta_{1} \\
\theta_{2}\end{array}$ & $\begin{array}{l}1,042 \\
0,126\end{array}$ & $\begin{array}{l}0,074 \\
0,780\end{array}$ & 51461 \\
\hline 3 & $\begin{array}{l}\text { ARIMA } \\
(1,1,0)\end{array}$ & $\emptyset_{1}$ & $-0,650$ & 0,104 & 57160 \\
\hline 4 & $\begin{array}{l}\text { ARIMA } \\
(2,1,0)\end{array}$ & $\begin{array}{l}\emptyset_{1} \\
\emptyset_{2}\end{array}$ & $\begin{array}{l}-0,657 \\
-0,042\end{array}$ & $\begin{array}{l}0,119 \\
0,921\end{array}$ & 60508 \\
\hline
\end{tabular}

Setelah nilai parameter ditemukan, maka disimpulkan bahwa model ARIMA (p,d,q) ditentukan dengan nilai error terkecil, dalam hal ini dapat dilihat pada tabel 4.12 pada kolom MSE ditemukan nilai error terkecil dengan angka 50300, yang berarti model yang akan digunakan sebagai peramalan untuk kertas art cartoon 230 gram adalah model ARIMA $(0,1,1)$.

Sedangkan untuk hasil estimasi parameter model ARIMA untuk kertas art cartoon 260 gram sebagai berukut.

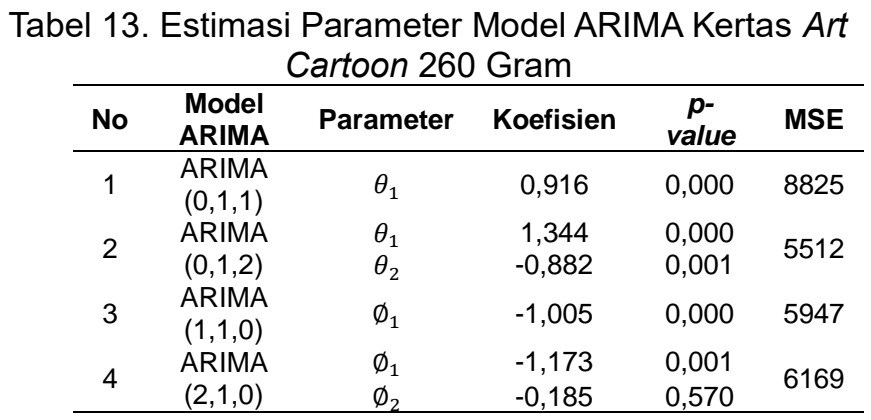

Setelah nilai parameter ditemukan, maka disimpulkan bahwa model ARIMA (p,d,q) ditentukan dengan nilai error terkecil, dalam hal ini dapat dilihat pada tabel 4.15 pada kolom MSE ditemukan 
nilai error terkecil dengan angka 5512, yang berarti model yang akan digunakan sebagai peramalan untuk kertas art cartoon 230 gram adalah model ARIMA $(0,1,2)$.

3. Verifikasi Parameter

Tahap verifikasi parameter merupakan tahapan yang harus dilalui setelah model ARIMA ditemukan dimana pada tahapan ini berguna untuk menguji kelayakan model ARIMA terhadap data yang akan digunakan untuk peramalan. Dalam tahapan verifikasi parameter terdapat 2 tahap uji yaitu uji signifikansi parameter dan uji kesesuaian model.

Uji signifikan parameter merupakan sebuah uji yang bertujuan untuk membuktikan bahwa parameter ARIMA signifikan/sesuai terhadap data. Berikut uji signifikansi parameter kertas art cartoon 230 gram:

\begin{tabular}{cccc} 
Tabel 14. Uji Signifikan Parameter & Kertas & Art & Cartoon 230 Gram \\
\hline Model ARIMA & Parameter & $\boldsymbol{p}$-value & Keputusan \\
\hline ARIMA $(0,1,1)$ & $\theta_{1}$ & 0,000 & Signifikan \\
ARIMA $(0,1,2)$ & $\theta_{1}$ & 0,074 & Tidak Signifikan \\
ARIMA $(1,1,0)$ & $\theta_{2}$ & 0,780 & Tidak Signifikan \\
ARIMA $(2,1,0)$ & $\emptyset_{1}$ & 0,104 & Tidak Signifikan \\
& $\emptyset_{1}$ & 0,119 & Tidak Signifikan \\
\hline
\end{tabular}

Model ARIMA yang signifikan terhadap model adalah model ARIMA $(0,1,1)$ dengan nilai $p$-value pada parameter $\theta_{1}=0,000$.

Berikut hasil uji signifikansi model ARIMA pada kertas art cartoon 260 gram:

\begin{tabular}{cccc} 
Tabel 15. Uji Signifikan Parameter & Kertas & Art & Cartoon 260 Gram \\
\hline Model ARIMA & Parameter & $\boldsymbol{p}$-value & Keputusan \\
\hline ARIMA $(0,1,1)$ & $\theta_{1}$ & 0,000 & Signifikan \\
ARIMA $(0,1,2)$ & $\theta_{1}$ & 0,000 & Signifikan \\
ARIMA $(1,1,0)$ & $\theta_{2}$ & 0,001 & Signifikan \\
ARIMA $(2,1,0)$ & $\emptyset_{1}$ & 0,000 & Signifikan \\
& $\emptyset_{1}$ & 0,001 & Signifikan \\
\hline
\end{tabular}

Berdasarkan tabel 4.32, maka dapat dilihat bahwa model ARIMA $(0,1,1)$, ARIMA $(0,1,2)$, ARIMA $(1,1,0)$ signifikan terhadap data, sedangkan model ARIMA $(2,1,0)$ yang memiliki nilai $p$-value pada parameter $\emptyset_{2}$ tidak signifikan karena $\mathrm{p}$-value $>\alpha$.

Untuk mengetahui apakah residual bersifat acak maka akan dilakukan uji Ljung Box pada kertas art cartoon 230 gram sebagai berikut:

Tabel 16. Uji Ljung-Box Kertas Art Cartoon 230 Gram

\begin{tabular}{cccccc}
\hline Model ARIMA & Lag & Chi-square & DF & p-value & Keputusan \\
\hline ARIMA $(0,1,1)$ & 12 & 7,94 & 10 & 0,634 & Tidak Signifikan \\
ARIMA $(0,1,2)$ & 12 & 6,92 & 9 & 0,646 & Tidak Signifikan \\
ARIMA $(1,1,0)$ & 12 & 8,77 & 10 & 0,554 & Tidak Signifikan \\
ARIMA $(2,1,0)$ & 12 & 9,09 & 9 & 0,429 & Tidak Signifikan \\
\hline \multicolumn{7}{c}{ Tabel } & 17. Uji & Ljung-Box Kertas & Art Cartoon 260 Gram \\
\hline Model ARIMA & Lag & Chi-square & DF & p-value & Keputusan \\
\hline ARIMA $(0,1,1)$ & 12 & 13,11 & 10 & 0,218 & Tidak Signifikan \\
ARIMA $(0,1,2)$ & 12 & 8,64 & 9 & 0,471 & Tidak Signifikan \\
ARIMA $(1,1,0)$ & 12 & 6,94 & 10 & 0,731 & Tidak Signifikan \\
ARIMA $(2,1,0)$ & 12 & 8,41 & 9 & 0,493 & Tidak Signifikan \\
\hline
\end{tabular}

Uji residual berdistribusi normal dilakukan dengan menggunakan uji Kolmogorov Smirnov kertas art cartoon 230 gram sebagai berikut:

Tabel 18. Uji Kolomogorov Smirnov Kertas Art Cartoon 230 Gram

\begin{tabular}{ccc}
\hline Model ARIMA & $\boldsymbol{p}$-value & Keputusan \\
\hline ARIMA $(0,1,1)$ & 0,030 & Signifikan \\
ARIMA $(0,1,2)$ & $>0,150$ & Tidak Signifikan \\
ARIMA $(1,1,0)$ & 0,048 & Signifikan \\
ARIMA $(2,1,0)$ & 0,053 & Tidak Signifikan \\
\hline
\end{tabular}


Berikut hasil uji kolmogorov smirnov data kertas art cartoon 260 gram:

Tabel 19. Uji Kolmogorov Smirnov Kertas Art Cartoon 260 Gram

\begin{tabular}{ccc}
\hline Model ARIMA & $\boldsymbol{p}$-value & Keputusan \\
\hline ARIMA $(0,1,1)$ & $>0,150$ & Tidak Signifikan \\
ARIMA $(0,1,2)$ & $<0,010$ & Signifikan \\
ARIMA $(1,1,0)$ & $>0,150$ & Tidak Signifikan \\
ARIMA $(2,1,0)$ & $>0,150$ & Tidak Signifikan \\
\hline
\end{tabular}

Kemudian didapatkan hasil verifikasi parameter kertas art cartoon 230 gram sebagai berikut:

Tabel 20. Verifikasi Parameter Kertas Art Cartoon 230 Gram

\begin{tabular}{ccccc}
\hline Model ARIMA & Signifikan & Residual Acak & Residual Normal & MSE \\
\hline ARIMA $(0,1,1)$ & Ya & Tidak & Ya & 50300 \\
ARIMA $(0,1,2)$ & Tidak & Tidak & Tidak & 51641 \\
ARIMA $(1,1,0)$ & Tidak & Tidak & Ya & 57160 \\
ARIMA $(2,1,0)$ & Tidak & Tidak & Tidak & 60508 \\
\hline
\end{tabular}

Dari hasil pada tabel 20 , maka didapatkan model ARIMA $(0,1,1)$ yang memenuhi signifikan dan residual berdistribusi normal serta memiliki nilai MSE yang kecil dengan model matematis ARIMA $(0,1,1)$

$$
f_{t}=X_{t-1}-\theta_{1} e_{t-1}
$$

Tabel 21. Verifikasi Parameter Kertas Art Cartoon 260 Gram

\begin{tabular}{ccccc}
\hline Model ARIMA & Signifikan & Residual Acak & Residual Normal & MSE \\
\hline ARIMA $(0,1,1)$ & Ya & Tidak & Tidak & 8825 \\
ARIMA $(0,1,2)$ & Ya & Tidak & Ya & 5512 \\
ARIMA $(1,1,0)$ & Ya & Tidak & Tidak & 5947 \\
ARIMA $(2,1,0)$ & Tidak & Tidak & Tidak & 6169 \\
\hline
\end{tabular}

Model ARIMA yang ditemukan untuk kertas art cartoon 260 gram adalah model ARIMA $(0,1,2)$ dengan nilai MSE 5512 dengan model matematis ARIMA $(0,1,2)$ sebagai berikut :

$$
f_{t}=X_{t-1}-\theta_{1} e_{t-1}-\theta_{2} e_{t-2}
$$

4. Hasil

a. Hasil ramalan untuk kertas art cartoon 230 gram

Dengan model ARIMA $(0,1,1)$ maka didapatkan hasil peramalan untuk bulan Mei 2019 dengan model matematis berikut:

$$
f_{22}=X_{21}-\theta_{1} e_{21}
$$

Kemudian didapatkan hasil untuk peramalan bulan Mei dan Juni 2019 sebagai berikut :

$$
\begin{aligned}
& \text { Mei } 2019=297 \\
& \text { Juni } 2019=305
\end{aligned}
$$

b. Hasil ramalan untuk kertas art cartoon 260 gram

Dengan model ARIMA $(0,1,2)$ didapatkan hasil untuk peramalan bulan Mei dan Juni 2019 sebagai berikut:

Mei $2019=122$

Juni $2019=330$

5. Tingkat Kesalahan

a. MSE (Mean Square Error)

Tabel 22. Nilai MSE Kertas Art Cartoon 230 dan 260 Gram

\begin{tabular}{ccccc}
\hline Bulan/Tahun & $\begin{array}{c}\text { Jenis } \\
\text { Kertas }\end{array}$ & Nilai Actual & Nilai Prediksi & MSE \\
\hline Mei/2019 & \multirow{2}{*}{230 gram } & 205 & 297 & 391,00 \\
Juni 2019 & 328 & 305 & \\
Mei/2019 & \multirow{2}{*}{260 gram } & 103 & 122 & 468,04 \\
Juni/2019 & 228 & 330 & \\
\hline
\end{tabular}

Pada tabel 4.45 dijelaskan bahwa tingkat MSE untuk kertas art cartoon 230 gram adalah 391 , sedangkan tingkat MSE pada kertas art cartoon 260 gram adalah 468.

b. MAPE (Mean Absolute Percentage Error)

Nilai MAPE yang telah ditemukan pada peramalan kertas art cartoon 230 gram dan 260 gram dapat dilihat pada 23 sebagai berikut: 
Tabel 23. Nilai MAPE Kertas Art Cartoon 230 dan 260 Gram

\begin{tabular}{ccccc}
\hline Bulan/Tahun & Kertas & Nilai Actual & Nilai Prediksi & MSE \\
\hline Mei/2019 & \multirow{2}{*}{230 gram } & 205 & 297 & \multirow{2}{*}{$21,74 \%$} \\
Juni 2019 & \multirow{2}{*}{260 gram } & 103 & 305 & \\
Mei/2019 & 228 & 122 & \multirow{2}{*}{$22,87 \%$} \\
Juni/2019 & & & 330 & \\
\hline
\end{tabular}

Dari tabel 23 diatas, sesuai dengan taraf signifikansi nilai pada landasan teori, nilai MAPE yang diperoleh dari hasil peramalan kertas art cartoon berada dalam kisaran $20-50 \%$ yang berarti peramalan layak/memadai.

Berikut tabel perhitungan tingkat kesalahan untuk kertas art cartoon 230 gram dan 260 gram pada tabel 24.

Tabel 24. Tingkat Kesalahan Kertas Art Cartoon 230 dan 260 Gram

\begin{tabular}{cccccc}
\hline Bulan/Tahun & Kertas & Nilai Actual & Nilai Prediksi & MSE & \\
\hline Mei 2019 & \multirow{2}{*}{ 230 gram } & 205 & 297 & 391,00 & $21,74 \%$ \\
Juni 2019 & & 328 & 305 & & \\
Mei 2019 & \multirow{2}{*}{260 gram } & 103 & 122 & 468,04 & $22,87 \%$ \\
Juni 2019 & & 228 & 330 & & \\
\hline
\end{tabular}

\section{Kesimpulan}

Berdasarkan hasil analisis yang telah dilakukan pada bab-bab sebelumnya, maka dapat disimpulkan sebagai berikut:

1. Model ARIMA untuk kertas art cartoon 230 gram yang didapatkan dari minitab adalah ARIMA $(0,1,1)$ dengan nilai prediksi di bulan Mei 2019 adalah 297 dan pada bulan Juni 2019 adalah 305 dengan tingkat MSE 391,00 dan MAPE 21,74\%.

2. Model ARIMA untuk kertas art cartoon 260 gram yang didapatkan dari minitab adalah ARIMA $(0,1,2)$ dengan nilai prediksi di bulan Mei 2019 adalah 122 dan pada bulan Juni 2019 adalah 330 dengan tingkat MSE 468,04 dan MAPE 22,87\%.

3. Proyeksi peramalan pada kertas art cartoon dengan menggunakan metode ARIMA mengalami penuruan pada bulan Mei 2019 dan mengalami kenaikan pada bulan Juni 2019.

4. Peramalan pada kertas art cartoon 230 dan 260 gram memiliki taraf signifikan nilai MAPE yang berada pada taraf $20-50 \%$ yang berarti peramalan layak atau memadai.

Dari kesimpulan diatas, maka penulis dapat memberikan saran antara lain:

1. Dari hasil yang sudah dilakukan, diharapkan dapat memberi masukan kepada Yudharta Advertising dalam mengambil keputusan terutama dalam memutuskan besarnya jumlah kertas yang harus disediakan untuk produksi agar dapat memperlancar proses produksi dan dapat memenuhi permintaan konsumen.

2. Perlu dilakukan penelitian lebih lanjut menggunakan metode peramalan lain agar didapatkan hasil yang lebih bagus.

\section{References}

[1] M. Okta Riyana, "SKRIPSI MAYA," Universitas Islam Negeri Raden Intan Lampung, 2018.

[2] Herjanto, Eddy. 2010, Manajemen Operasi, ed: Revisi, Gramedia, Jakarta.

[3] Assauri, Sofjan. 2008. Manajemen Produksi dan Operasi, Jakarta: LPFEUI.

[4] Prawirosentono, Suryadi. 2002. Manajemen Sumberdaya Manusia: Kebijakan Kinerja Karyawan. Edisi I. Cetakan kedelapan. BPFE. Yogyakarta.

[5] Baruto, 2002. Perencanaan dan Pengendalian Produksi, Ghalia Indonesia, Jakarta.

[6] Kholmi, Masyiyal, 2003. Akuntansi Biaya, Edisi Revisi. Yogyakarta. Aditia Media.

[7] Tholib, Muh. 2016. Forecasting Sales in Order Planning Company Furnituture (Case Study CV. Budi Luhur Sidoarjo). Skripsi Institut Teknologi Sepuluh November.

[8] Oktarina, Tri, \& Rasmila, D., 2018. Peramalan Produksi Crude Palm Oil (CPO) Menggunakan Metode ARIMA Pada PT. Sampoerna Agro Tbk. Seminar Nasional Sistem Informasi Informatika Indonesia. 